\title{
A rare Case of Papillary Thyroid Cancer: Pituitary Methastasis
}

Authors 1)Özlem Zeynep Akyay, 2) Alev Selek, 3)Berrin Çetinarslan, 4) İlhan Tarkun 5) Zeynep Cantürk 6) Adnan Batman

Hospital: Kocaeli Universty Endocrinology and metabolism Section, Kocaeli, Turkey

\section{Introduction}

Papillary thyroid carcinoma (PTC) is a common malignancy with a rising incidence possibly, but not solely, due to early diagnosis. PTC generally has a favorable prognosis, until distant metastases appear. Distant metastases, primarily to lungs and bones, are rare and only exceptionally are the first manifestation of the disease. Distant metastases are found in 1-9\% of newly diagnosed PTC while in $7-23 \%$ of patients during follow-up. Cerebral metastasis is seen in \%0.4-1.2 of patients with distant organ metastasis. There are only 14 patients of DTC with pituitary metastasis reported in the literature. Here, we report a papillary thyroid carcinoma (PTC) patient represented with pituitary metastasis
68 years old male patient has admitted to our hospital with a growing tumor on his anterior chest wall. On imaging there was a $5 \mathrm{~cm}$ mass on the manubrium sterni. The patient was referred to our clinic as the biopsy of the mass revealed PTC metastasis. During clinical evaluation there was $5 \mathrm{~cm}$ hypoecoic, hypervascular nodule on left thyroid lobe. Also there were high Fluorodeoxyglucose (FDG) affinity on pituitary region, thyroid left lobe, sternum, first lomber vertebrae and left humerus on positron emission tomography -computerized tomography (PET- CT) consistent with metastasis. Total thyroidectomy with lymph node dissection was performed and pathology revealed poorly differantiated insular type PTC. The pituitary lesion was also operated but could only be partially resected. The pituitary pathology showed PTC methastasis. The sternal mass could not be operated due to high morbidity and invasiveness. Radio-frequency ablation was performed but the mass was continued grow. After 3 months arterial embolisation was performed to the lesion. As the pituitary lesion was very close to the brain stem structures, radio-iodine treatment was decided to be contraindicated. 36 gray conventional radiation therapy was given to the pituitary region. During all these treatment procedures sorafenib $2 \times 400$ medical treatment was also initiated. He is still as follow up with stable disease

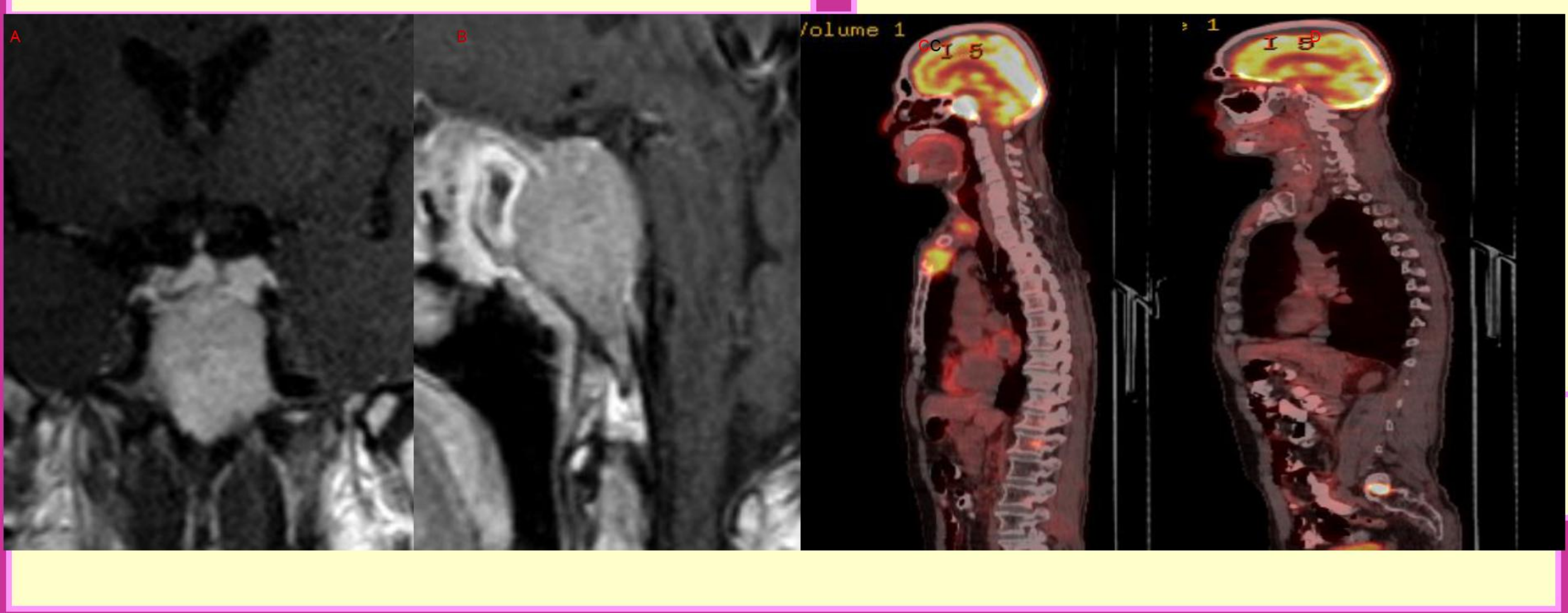

Conclusions:

The pituitary methastasis of PTC is a rare entity. The management strategy of distant organ metastasis of PTC should include multidiciplinary approach
Figure A,B: Pituitary metastases

Figure C:pituitary, sternum, vertebral metastasisi

Figure D: sacrum metastasis

\section{References:}

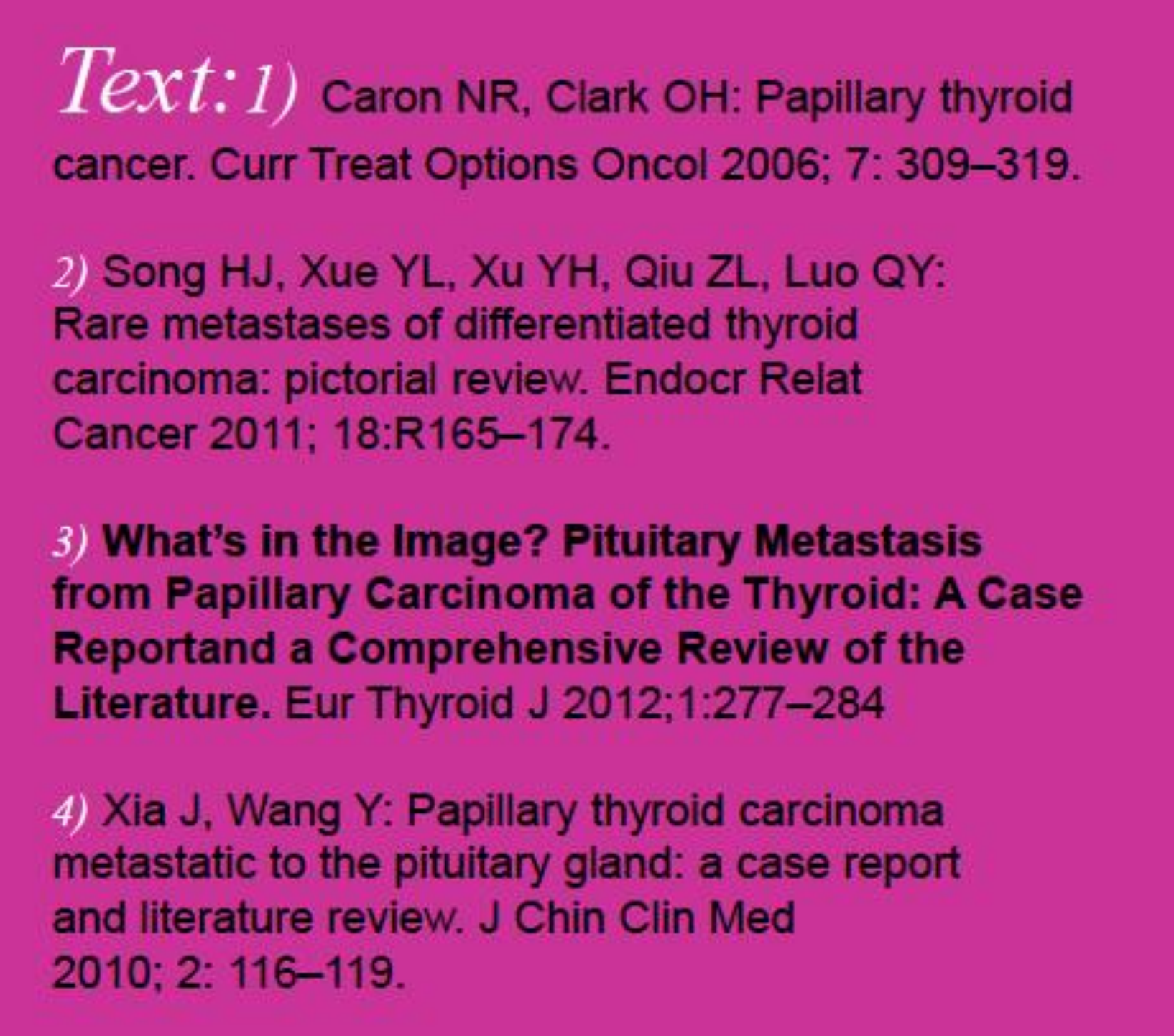
cancer. Curr Treat Options Oncol 2006; 7: 309-319. Song HJ, Xue YL, Xu YH, Qiu ZL, Luo QY: carcinoma: pictorial review. Endocr Relat What's in the Image? Pituitary Metastasis Reportand a Comprehensive Review of the

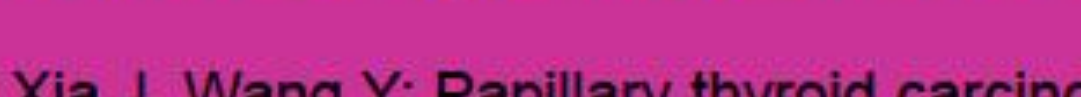
etastatic to the pituitary gland: a case report
diterature review. J Chin Clin Med 